\title{
Reform of Nursing Education in Vocational School
}

\author{
Liu Huan \\ School of nursing \\ Jiangxi University of Technology
}

\begin{abstract}
Medical nursing education aims at improving students' professional ability and cultivating practical medical talents who meet social needs. With the constant change of medical mode and attitudes, comprehensive clinical system cursing and the new form of hospital development, nursing education also carry on education reform actively. This paper discusses how to further enhance teaching methods which integrates vocational ability such as students' practical ability, judgment analysis capability, ability to solve practical problems, communication skills and thinking ability on the basis of consolidating existing operations in teaching to reform ,thus to cultivate medical nursing talents meeting social needs.
\end{abstract}

Keywords-Nursing education, creation, reform, medical equipment

\section{INTRODUCTION}

When curriculum reform with the purpose of reducing class hour is popular, we combine advanced teaching concept and the development trend of nursing in China, take another route and put forward the topic design idea which unites theory and practice, education resource and social attributes .According to years of teaching experience and feedback of both students and teachers, summarize problems(anatomical terms numerous, hard to memorize but easy to forget, jargon awkward-sounding and memorize mechanically )which occur in teaching .By means of amending syllabus, integrating educational resources, carry on various teaching, integrate medical humanism and developing interactive digital learning platform to change the existing teaching mode, thus to form a complete integrated teaching system and drive a comprehensive reform of vocational nursing curriculum.

According to problems existing in teaching, this paper proposes that teacher should actively stimulate students' motivation and interest by teaching method reform and help students to understand what they learn. In imparting knowledge, they should cultivate students' clinical thinking ability with purpose and plan. They should not only make them have basic professional knowledge and skills but also should make students have certain judgment ability, evaluation ability, psychology nursing ability and health propaganda ability.

\section{PROBLEMS OF NURSING EDUCATION}

Nursing education is an important part of medical education. At present, in our country, nursing education develops in multiple level, including specialist, undergraduate ,even graduate, there are also lower level such as secondary vocational. However, nursing has a profession access, which is they have to pass nursing licensing examination before they engage in clinical care. It clearly stipulates in Nursing Licensing Examination syllabus issued in 2011 that anatomy, physiology, pathology and pathophysiology , pharmacology , immunology medical microbiology and parasites are all the basis of modern medicine .Among them , physiology , pathophysiology, pharmacology consist of "three function" of modern medical function

In recent years, according to nursing licensing examination syllabus, many medical schools constantly amend teaching plan to adapt to the requirement of nursing teaching. Currently, most nursing major in institutes are three -year college. Considering students need to conduct a one-year clinical practice, many schools compresses the class hours of basic medical disciplines and integrates some curriculum to ensure the clinical time. Due to the large reducing of some of the class hours of basic medical, experimenting teaching is paid less attention. Experimenting teaching is supposed to be an important part of teaching, but it is regarded as the auxiliary of theory by some schools. Most experimenting classes are opened according to theoretical course, independently and only emphasize the integrity. The teaching contents are focused on verification experiment. The basic teaching method is to instill and students in experimental class are completely passive. Some schools replace experiment with teaching video, even some 
schools don't open them. This seriously affects teaching quality.

\section{THE NECESSITY OF NURSING EDUCATION REFORM}

A. It's required by nursing education development to open medical basic comprehensive experiment.

Nursing education is an important component of our macro-scope medical education, which takes the hard task of cultivating qualified nursing talents for health service. Nursing education develops with the development of society and medical education. Under our traditional medical teaching mode, it mainly depends on the teaching method of the Soviet Union, emphasizing imparting existing knowledge other than cultivating competence and mainly adopting teacher and textbook-oriented closed education means. The medical mechanism experimenting teaching is to set up teaching lab and the main purpose of medical basic experimenting course is to verify the theory of the field involved.

\section{B. To set up medical basic comprehensive experiment is the requirement of cultivating high-quality inter-disciplinary teachers.}

Under the influence of traditional teaching mode, most medical-based teachers in our nursing teachers only undertake 1 course, the study direction is a certain direction of one curriculum and the knowledge structure is relatively systematic and independent. So the synthesized knowledge application ability of teachers is influenced. The opening of medical comprehensive experiment is helpful for medical-based teachers to use medical theory knowledge and experiment technology, according to the needs of students in vocational schools, choose the proper and feasible experimental technique and methods, design comprehensive and creative experiment ; Carrying on medical basis comprehensive experiment study is helpful for teachers and students to fully play their intelligence and wisdom in the process of experimental teaching to achieve the teaching goal of cultivating creativity of students and improving students' comprehensive quality.

\section{SUGGESTIONS OF REFORM OF TEACHING METHOD}

Regarding to the above problems existing in current medical education, this paper proposed a variety of creative teaching methods including multimedia teaching, situational teaching approach, role-playing approach and heuristic mode of teaching .etc

\section{Compile experimental teaching materials suitable for specialty requirement}

On the premise of united thoughts, refer to the functional experimental assisting teaching material used by related colleges, organize teachers of physiology, pathophysiology and pharmacology discuss together experiment content, compile nursing medical functional experimental teaching material, design comprehensive lab suitable for students' characteristics to make students more interested in experimental lesson and better effect of experimental lesson. In particular, we combine with our current lab condition and students' major to compile nursing medical functional experimental teaching material on the premise of highlighting nursing characteristic.

\section{Establish functional lab suitable for curriculum and the related management mechanism}

In order to ensure the teaching quality of medical functional lab, the college invests a certain amount of capital every year to gradually improve the lab equipment, such as purchasing functional virtual lab. Before carry on experiment on animals, students can do the virtual experiments over and over again to get familiar with the process and steps of experiment. Meanwhile, colleges also set up the lab management rules suitable for curriculum and changed the old mode which is according to subject and major setting, the teaching and research section is in charge. The working efficiency is low, and resource, equipment and personnel can't be fully used.

E. It proves the teaching quality of the whole basic subject and the constant improvement of teachers' quality.

Functional experimental lab teaching reform greatly improves the teaching ability of teachers. First, basic subject teachers should not only study the newest knowledge of their own field but also should know some new methods, new technology and new medicine in nursing clinical work. Since the teachers and lab assistant are from different subjects, it's necessary to know the teaching content and requirement of the related subject to better answer questions asked by students in the lab. 


\section{CONCLUSION}

Teaching methods are various in nursing education, so we must be flexible and comply with "teaching has a method but not fixed; the precious is to have a point". Teach the students according to their aptitude, according to the needs of students, teaching material content and characteristic. At the same time, timely adjust teaching methods according to students' feedback and suggestions, constantly improve and enhance teaching level. In nursing education reform, nursing teachers must innovate their teaching thoughts, make progress in study, cultivate and improve the comprehensive quality and creativity of the nurses, constantly study new teaching mode and teaching method and cultivate practical nursing talents to meet the requirement of society and clinic.

\section{REFERENCES}

[1] Reilly D E, Oermann M H. Clinical teaching in nursing education[J]. Nln Publications, 1992, 36(15-2471):v-xiv, 1-507.
[2] Calvillo, E., Clark, L., Ballantyne, J. E., Pacquiao, D., Purnell, L. D., \& Villarruel, A. M. (2009). Cultural competency in baccalaureate nursing education.. Journal of Transcultural Nursing, 20(2), 137-145.

[3] Thompson D R, Watson R. Professors of nursing: What do they profess? - Nurse Education in Practice[J]. Nurse Education in Practice, 2006, 6(3):123-126.

[4] Norman L, Buerhaus P I, Donelan K, et al. Nursing students asses nursing education.[J]. Journal of Professional Nursing Official Journal of the American Association of Colleges of Nursing, 2005, 21(3):150-158.

[5] Ferrell B R, Virani R, Grant M, et al. End of life issues and nursing education.[J]. Imprint, 2000, 47(2):443-447.

[6] Beaulieu L P. Preceptorship and mentorship: bridging the gap between nursing education and nursing practice.[J]. Imprint, 1988, 35(2).

[7] Chally, P. S. "Moral and ethical development research in nursing education.." Nln Publications 15-2339(1990):33-47.

[8] Meakim, C, and A. B. Mckenzie. "Clinical simulation in nursing education.." Imprint 56.3(2009):40-42.

[9] Klimek M. Virtue, ethics, and care: developing the personal dimension of caring in nursing education. $[\mathrm{J}]$. Nln Publications, 1990, (41-2308):177-187.

[10] White, Alan. "Research in Nurse Education Today: do we mee our aims and scope" Nurse Education Today 22.1(2002):págs. 601-608.

[11] Hurley P M, Mcgriff E P. AIDS: its impact on nursing education and practice[J]. Imprint, 1989, 36(1).

[12] Ae., Newswanger. "Accreditation: quality assurance in nursing education.." Imprint 2(1979):40-41,77. 